\title{
A Circularly Polarized Semi-Symmetric Curvature Slot Fractal Antenna for Gain Enhancement
}

\author{
Bandhakavi S. Deepak ${ }^{1, *}$, Boddapati T. P. Madhav ${ }^{1}$, Badisa Anil Babu ${ }^{1}$ and Kosuru Sri Rama Murthy² \\ ${ }^{1}$ Antennas and Liquid Crystals Research Centre, Department of Electronics and Communication Engineering, Koneru Lakshmaiah \\ Education Foundation, Vijayawada, AP, India \\ ${ }^{2}$ Department of ECE, Miracle Education Society Group of Institutions, Bhogapuram, AP, India
}

Received 16 October 2020; Accepted 1 January 2021

\begin{abstract}
A Novel Semi-Symmetric curvature slot impregnated Decagonal shaped microstrip patch antenna with miniaturized dimensions of $20 \times 12 \mathrm{~mm}^{2}$ has been designed and analysed for its working in the frequency range of 4.56 to $12.42 \mathrm{GHz}$. This paper focuses more on how geometrical changes in the slots affects the impedance, radiation pattern, gain and polarization of the microstrip patch antenna with Defected Ground Structure (DGS). The emphasis is on achieving adequate antenna impedance matching with the help of a nonlinear, semi-symmetric curvature slot to improve the peak gain and to achieve circular polarization. Despite being a single element with wideband characteristics, an average peak gain of $12.96 \mathrm{~dB}$ has been recorded for the operating bandwidth of $7.86 \mathrm{GHz}$. Simulated and measured results of the proposed antenna are analysed w.r.t the Return Loss characteristics pertaining under $-10 \mathrm{~dB}$.
\end{abstract}

Keywords: Semi-Symmetric Curvature Slot, Decagonal Patch, V-Groove in Defected Ground Plane, Non-Linearity, Impedance Matching, Peak Gain \& Circular Polarization.

\section{Introduction}

Upgradation of literature in the field of antennas is cruising with a tremendous pace, as many varieties of antennas are taking shape in the shortest possible intervals. But it is technically proven to be true that, the gain-bandwidth compromise has its own impact and influence on the single element antennas. Therefore, the antenna arrays have become more popular these days for maintaining good gains over the operating bands of frequencies. Imagine if a single element can alone accomplish it! This is of course not out of reach and well on the cards. Geometrical changes in the slots of microstrip patch antennas are very likely to produce the desired results. Let's have a quick review of literature on multiband and wideband antennas with average peak gain as the metric for comparison.

Sanjay Chouhan [1] proposed a Spider-shaped fractal MIMO antenna for WLAN/WiMAX/Wi-Fi/Bluetooth/Cband applications for which the average peak gain achieved is $9.8 \mathrm{~dB}$. Majed O. Dwairi [2] introduced Design and Performance Analysis of Fractal Regular Slotted-Patch Antennas for Ultra-Wideband Communication Systems with average peak gains ranging from $3.5 \mathrm{~dB}$ to $4 \mathrm{~dB}$. Mohd Gulman Siddiqui [3] has analysed the Koch-Sierpinski Fractal Microstrip antenna for $\mathrm{C} / \mathrm{X} / \mathrm{Ku}$-band applications. Inkwinder Singh Bangi [4] published an article on Moore, Minkowski and Koch Curves Based Hybrid Fractal Antenna for Multiband Applications and recorded that the average peak gain obtained over the operating bandwidth is around 7 dB. J. A. Tirado-Mendez [5] has analysed Inscribed Fibonacci Circle Fractal in a Circular Radiator for UltraWideband Antenna Operation and Size Reduction and found

*E-mail address: savi.lonare@gmail.com

ISSN: 1791-2377 @ 2021 School of Science, IHU. All rights reserved.

doi:10.25103/iestr.143.14 that the average peak gain obtained is $1 \mathrm{~dB}$. R. L. Farias [6] proposed a Dual-Port Dual-Wideband Annular Slot Antenna with Stable Unidirectional Pattern, offering an average peak gain of $8.5 \mathrm{~dB}$.

Aliakbar Dastranj [7] designed A New Compact Circular Shape Fractal Antenna for Broadband Wireless Communication Applications and the average peak gain for the working bandwidth has been recorded as $3.7 \mathrm{~dB}$. Ushaben Keshwala [8] presented Honeycomb shaped Fractal Antenna with Defected Ground Structure for UWB applications, whose average peak gain is $3.11 \mathrm{~dB}$. The proposed Decagonal shaped microstrip patch antenna structure with a Semi-Symmetric closed curvature slot extruded at the centre has produced an impressive average peak gain of $12.96 \mathrm{~dB}$ for the operating bandwidth of 7.86 $\mathrm{GHz}$ (4.56 to $12.42 \mathrm{GHz}$ ), of course with the support of Vshaped groove embedded Defected Ground Structure (DGS).

\section{Design and Analysis}

The proposed Semi-Symmetric curvature slot microstrip patch antenna has been designed in the HFSS Software, with $20 \mathrm{~mm} \times 12 \mathrm{~mm}$ as the dimensions of FR4 (Glass Epoxy; $\boldsymbol{\epsilon}_{\boldsymbol{r}}=$ 4.4) substrate having a thickness of $1.6 \mathrm{~mm}$. Initially, the ground plane dimensions are also chosen as $20 \mathrm{~mm} \times 12 \mathrm{~mm}$, forming a complete ground plane at the bottom facet of the substrate. A Decagonal patch with a side length of ' $\boldsymbol{\alpha}$ ' $=$ $3.215 \mathrm{~mm}$ has been designed where, its diameter across five sides (D), perimeter (P) and total area (A) are computed with the help of the following expressions respectively:

$$
D=(1+\sqrt{5}) * a
$$


$P=10 * a$

$A=\left(\frac{5}{2}\right) * a^{2} * \sqrt{(5+2 * \sqrt{5})}$

More the discontinuities, more will be the radiating spots on the patch and therefore Decagonal geometry has got some good reason for being chosen in the proposed design. Later, the microstrip feed line is designed with the dimensions $10 \mathrm{~mm} \times 3 \mathrm{~mm}$ and blended with the Decagonal patch, constituting the basic design of the proposed model. The material chosen for the ground plane, microstrip patch and the feed line is PEC (Perfect Electric Conductor). The width of the strip line is optimized based on the following expression.

$$
w=\left[\frac{7.48 \times h}{e^{\left(\frac{z_{0} \sqrt{\varepsilon_{r}+1.41}}{87}\right)}}\right]-1.25 \times t
$$

Where,

$W$ is Width of the Feed-line

$Z_{0}$ is the Single Ended Impedance

$t$ is Trace Thickness

$h$ is Substrate Thickness

$\epsilon_{r}$ is Relative Dielectric Constant

As an improvement to the design for enhancing the operational characteristics, the length of the ground plane is shortened from $20 \mathrm{~mm}$ to $8.5 \mathrm{~mm}$ and an optimized V-shaped groove of side length $4.697 \mathrm{~mm}$ is introduced as the defected ground structure as shown in the Figure 2. In addition, a semi-symmetric curvature slot of height $9.6 \mathrm{~mm}$ (optimized) is etched from the patch. The V-shaped groove on the ground plane and the closed curvature slot on the patch in combination has got lot of significance, where the changes in the shape of semi-symmetric curvature slot and depth of $\mathrm{V}$-groove are being reasonably reflected in the characteristics of S11 (Return Loss), Gain, as well as Polarization. This particular design has unveiled the fact that curvature-based slots are much more efficient when compared to the regular polygonal geometry-based slots, in achieving wider bandwidths, as well as enhancing the gains of the microstrip patch antenna and obtaining Circular polarization.

The design of the proposed semi-symmetric curvature slot fractal antenna has been evolved through the iterations starting with the microstrip line, circular patch of radius $5 \mathrm{~mm}$, decagonal patch with full ground plane, then the optimized defected ground plane, followed by the inclusion of an optimized V-groove on the ground plane and finally the proposed model as shown in the Figure 1.

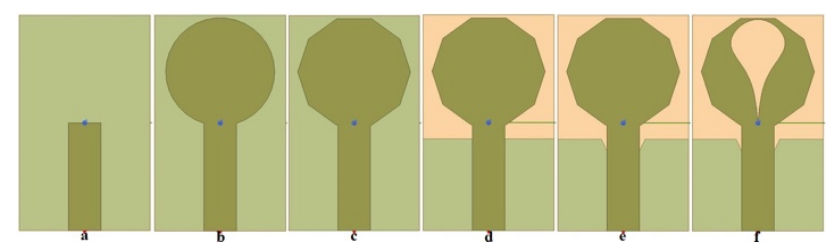

Fig. 1. Iteration wise Antenna Design (a) Iteration-0, (b) Iteration-1, (c) Iteration-2, (d) Iteration-3, (e) Iteration-4, (f) Proposed Model

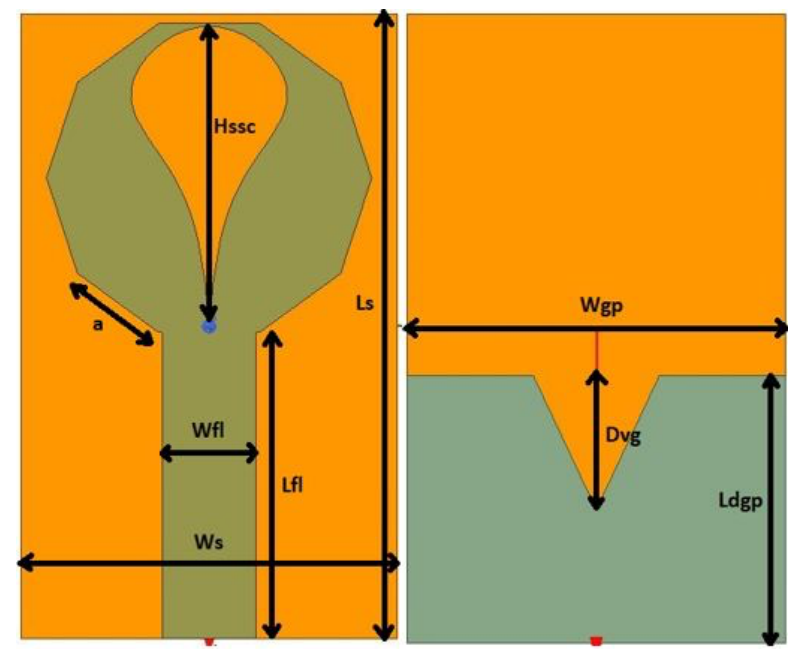

Fig. 2. Proposed Antenna Model

The Semi-Symmetric closed curvature slot in the proposed microstrip patch antenna is a heterogeneous curve (which is a combination of an Inverted Parabola and Neile's Semi-cubical Parabola), whose cartesian equations are expressed as following:

$y=-b x^{2}+c$ (expression for Inverted Parabola)

$y^{3}=m x^{2}$ (expression for Neile's Semi-cubical Parabola)(6)

Where, $m \& b$ are the slopes of Neile's Semi-cubical Parabola and Inverted Parabola respectively, and $\mathbf{c}$ is the $\mathbf{y}$ intercept.

The semi-symmetric curvature slot on the microstrip patch in line with the $\mathrm{V}$-groove on the ground plane induces non-linearity in the Decagonal patch structure leading to Circular polarization at the resonant frequencies. All the optimized design parameters of the proposed antenna are listed in Table 1.

Table 1. Optimized Design Parameters of the Proposed Antenna

\begin{tabular}{l|c|l|c}
\hline \multicolumn{1}{c|}{ Description of Parameter } & Value & \multicolumn{1}{c|}{ Description of Parameter } & Value \\
\hline Length of the Substrate (Ls) & $20 \mathrm{~mm}$ & $\begin{array}{l}\text { Side length of the Decagon (a) } \\
\text { Height of Semi-Symmetric Curvature Slot }\end{array}$ & $\begin{array}{c}3.215 \\
\mathrm{~mm}\end{array}$ \\
$\begin{array}{l}\text { Width of the Substrate (Ws) } \\
\text { (Hssc) }\end{array}$ & $12 \mathrm{~mm}$ \\
$\begin{array}{l}\text { Length of the Defected Ground Plane } \\
\text { (Ldgp) }\end{array}$ & $8.5 \mathrm{~mm}$ & $\begin{array}{l}\text { Length of the feed line (Lfl) } \\
\text { Width of Ground Plane (Wgp) } \\
\text { Depth of V-groove in the DGS (Dvg) }\end{array}$ & $12 \mathrm{~mm}$ \\
\hline
\end{tabular}


The reason behind achieving higher gains for the wide bandwidths with the insertion of optimized semi-symmetric curvature slot is the non-linear nature of the slot, which offers better impedance matching when compared to any other regular or linear geometrical shapes. The nonlinearity in the slot structure enables the exponentially changing impedances of the patch to get matched appropriately and thereby producing fruitful results w.r.t gain, bandwidth and polarization.

\section{Results and Discussion}

The simulation of designed antenna has been carried out in the HFSS software and various parameters such as Return loss, Gain, Radiation Pattern and Axial Ratio have been analysed. The forefront parameter which outlines the performance of the antenna is the Return loss (in dB). S11 gives the amount of power reflected back to the source in the form of decibels and the threshold for that is $\mathrm{S} 11<-10 \mathrm{~dB}$. With reference to this metric, the return loss has been analysed for all the iterations of the design including the final model as shown in Figure 3 (a). The S11 characteristics just got better and better as moved towards the proposed model starting from the iteration- 0 . These changes are a result of variations in the input impedance of the designed antenna. Inclusion of slots in the patch and in the groundplane caused variations in the input impedance of the antenna and therefore defected ground structure with extruded V-grove has produced better impedance matching and has let the return loss characteristics drift closer to -10 $\mathrm{dB}$, when compared with the former iteration results. Yet, the results were not up to the benchmark. The insertion of Semi-Symmetric curvature slot on the decagonal patch (proposed model) has offered much better impedance matching further and achieved a wideband of $7.86 \mathrm{GHz}$, operating from 4.56 to $12.42 \mathrm{GHz}$ range.
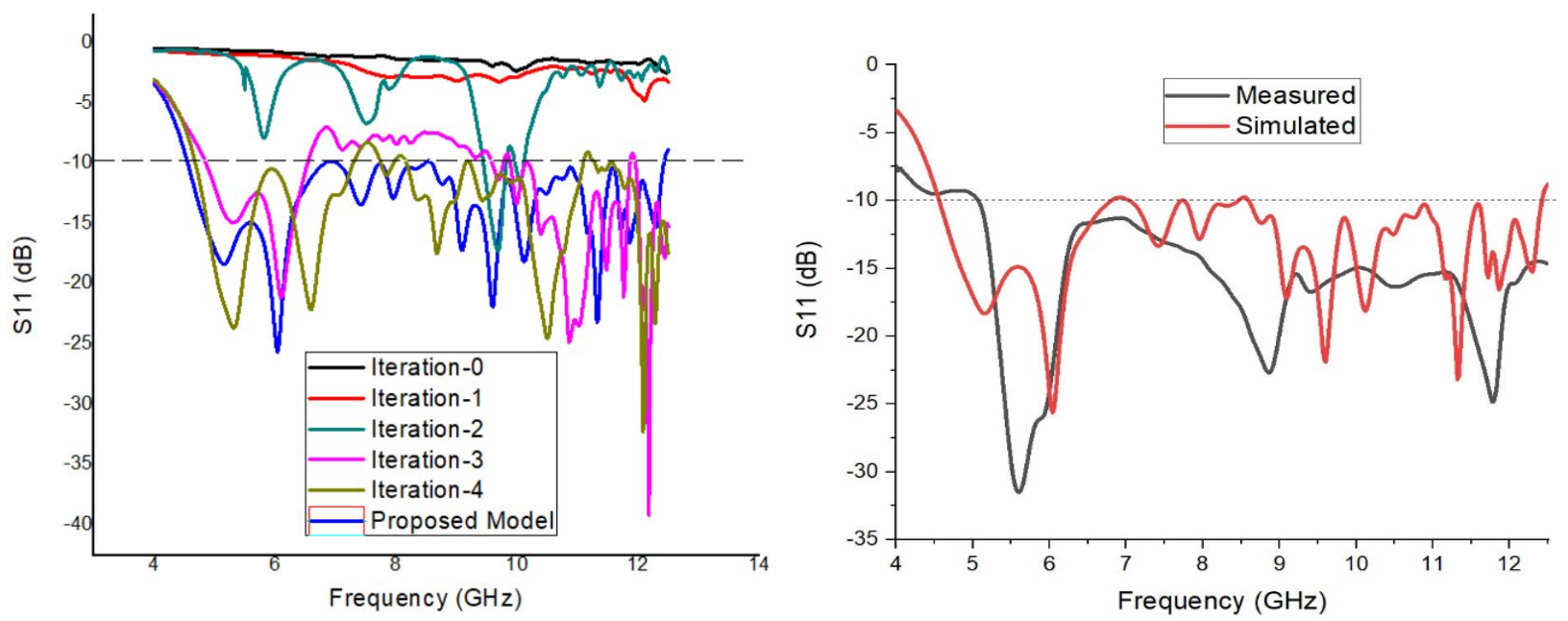

Fig. 3. Return loss characteristics of (a) All the Iterations, (b) Proposed Model (Simulated \& Measured)

The S11 result analysis has been performed for different geometrical slots such as pentagonal slot, triangular slot and symmetric curve slot prior to adopting the Semi-Symmetric curvature slot, where none of the former models have produced convincing results. The idea behind the thought of inculcating a semi-symmetric curvature slot is to induce non linearity in the patch, in order to match up with the exponentially varying input impedance of the patch antenna expressed as,

$$
Z_{i n}=Z_{0}\left(\frac{Z_{L}+j Z_{0} \tan (\beta l)}{Z_{0}+j Z_{L} \tan (\beta l)}\right)
$$

This theory has worked out quite well when implemented in the design and the S11 characteristics have suggested that the proposed antenna offers a broad bandwidth, which covers most of the UWB. The simulated and measured Return loss characteristics plot of the proposed model with optimized design parameter values is as shown in the Figure 3(b). The parametric analyses have been carried out for the designed antenna to optimize the results, and identified the best design facets in terms of results. Starting with the length of the ground plane (Ldgp), the parametric analyses have been done for depth of the Vgroove in the ground plane (Dvg), width of the feedline (Wfl), as well as the height of semi-symmetric curvature slot (Hssc) as shown in the Figures 4(a), 4(b), 4(c) and 4(d) respectively. The optimized design parameter values are Ldgp $=8.5 \mathrm{~mm}$, Dvg $=4.25 \mathrm{~mm}, \mathrm{Wfl}=3 \mathrm{~mm}$ and Hssc $=$ $9.6 \mathrm{~mm}$.

Inclusion of the nonlinear curvature slot on the patch and the V-groove in the ground plane has resulted in circular polarization along with wideband and high peak gains. The exponential nature of the curvature slot has significant contribution in obtaining the circular polarization. Normally the circular polarization exhibited by an antenna can be checked with the help of Axial Ratio (in dB), with the condition $\mathrm{AR}(\mathrm{dB})<3 \mathrm{~dB}$. The circularly polarized radiation patterns (both simulated and measured) at distinct frequencies are as shown in the Figure 5. The frequencies at which the antenna possesses circular polarization are as given in Table2. 
Table 2. Details of frequencies at which circular polarization is achieved

\begin{tabular}{c|c|c|c}
\hline \multirow{2}{*}{ S. No } & $\begin{array}{c}\text { Frequencies at which Circular Polarization is } \\
\text { Achieved (GHz) }\end{array}$ & \multirow{2}{*}{ Phi (in Degrees) } & \multirow{2}{*}{ Theta (in Degrees) } \\
\hline 1 & $8.6,11.54,11.68 \& 11.86$ & $0 \& 90$ & 0 \\
2 & $6.32,8.4-8.6,11.58 \& 12.14$ & 0 & 90 \\
3 & $7.8-7.95 \& 10.55-10.65$ & 90 & 90 \\
4 & $5.85-6.05,8.2 \& 10.28$ & 60 & 30 \\
\hline
\end{tabular}
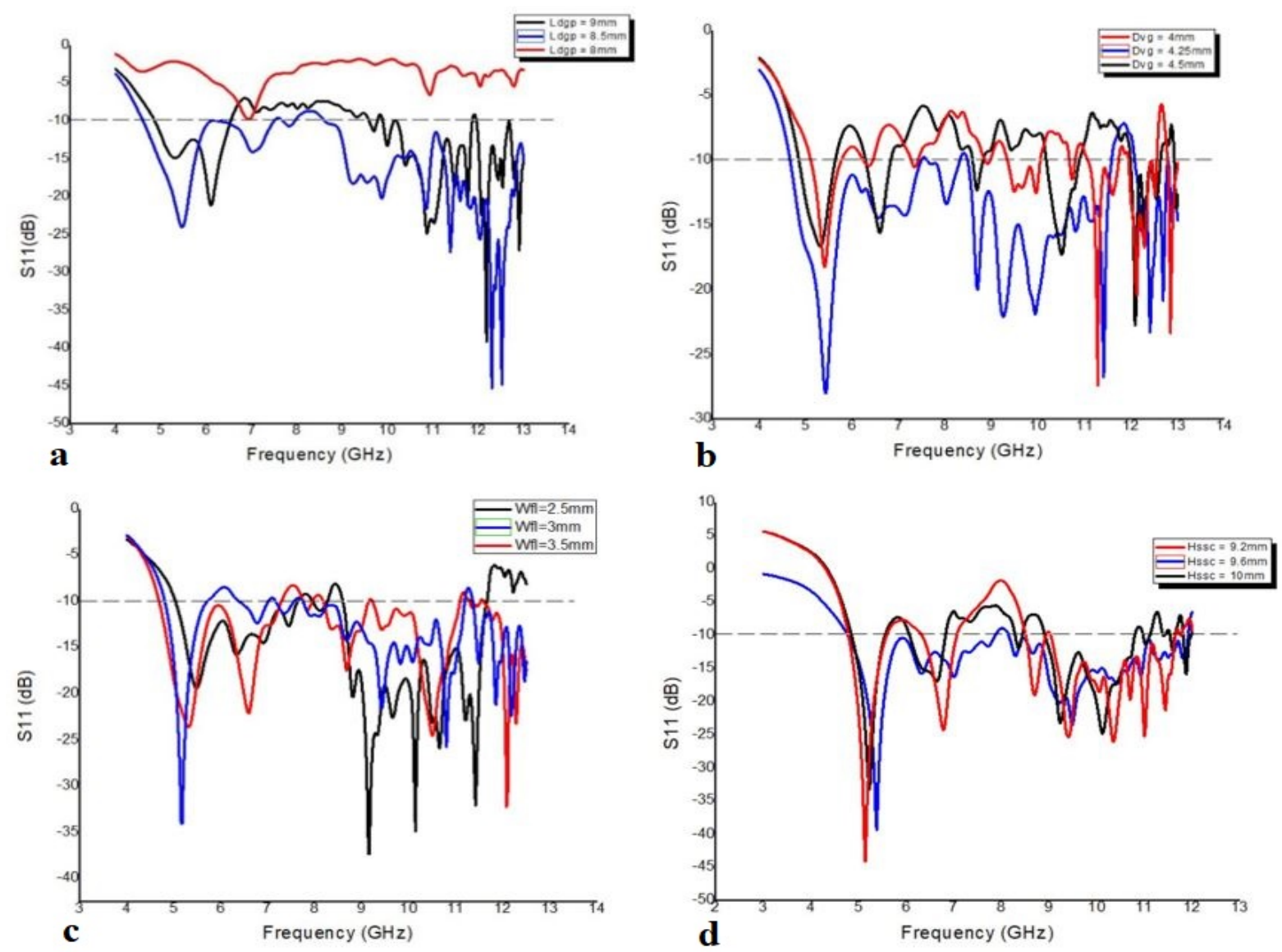

Fig. 4. S11 parametric analysis of (a) Length of the defected ground (Ldgp), (b) Depth of the V-groove in DGS (Dvg) (c) Width of the feed line (Wfl) and (d) Height of the semi-symmetric curvature slot (Hssc).

Table 3. Peak Gains and Radiation Efficiencies at distinct frequencies in the operating band

\begin{tabular}{c|c|c|c}
\hline S. No & Frequency (GHz) & Peak or Max. Gain (dB) & Radiation Efficiency (\%) \\
\hline 1 & 4.56 & 10.39 & 85.23 \\
2 & 4.9 & 8.94 & 88.91 \\
3 & 5.2 & 10.39 & 93.7 \\
4 & 5.5 & 11.28 & 95.63 \\
5 & 5.9 & 11.99 & 86.4 \\
6 & 6.42 & 13.51 & 85 \\
7 & 8.5 & 13.58 & 78.81 \\
8 & 10.68 & 15.60 & 74 \\
\hline
\end{tabular}

With reference to the Return loss characteristics, it is evident that the proposed antenna operates in the range of 4.56 and $12.42 \mathrm{GHz}$ frequencies, ticking for many practical applications such as ISM $(5.2 \& 5.8 \mathrm{GHz})$, WLAN $(5.2 / 5.8 \mathrm{GHz})$, WiMAX $(5.25-5.85 \mathrm{GHz})$, Wi-Fi $(4.9,5$ \& $5.9 \mathrm{GHz})$, ITU Radar Bands (C-band (5.25-5.95GHz) and Xband $(8.5-10.68 \mathrm{GHz}))$, Miracast $(5 \mathrm{GHz})$, Satellite Uplink (C-band (5.925-6.425GHz)) and Satellite Downlink (X-band $(11.7-12.2 \mathrm{GHz}))$. The simulated and measured results of circularly polarized Radiation Patterns for the proposed antenna are observed at some of the application frequencies $(5.2,5.9,8.5$ and $11.98 \mathrm{GHz})$ as shown in the Figure 6. The simulated peak gains (dBs) registered at the selected application frequencies 5.2, 5.9, 8.5 \& $11.98 \mathrm{GHz}$ are 10.39, $11.99,13.58 \& 17.01 \mathrm{dBs}$ respectively.

Peak Gain (Max. Gain) and Radiation Efficiency Vs Frequency have been plotted for distinct frequencies in the range of 4.56 to $12.42 \mathrm{GHz}$ as shown in Figure 7. The maximum peak gain obtained is $17.01 \mathrm{~dB}$ at $11.98 \mathrm{GHz}$ with a minimum peak gain of $8.94 \mathrm{~dB}$ recorded at $4.9 \mathrm{GHz}$. The 
maximum and the minimum radiation efficiencies achieved are $95.63 \%$ and $74 \%$ at $5.5 \mathrm{GHz}$ and $11.98 \mathrm{GHz}$ respectively. The peak gains and radiation efficiencies obtained at various frequencies are as mentioned in Table 3. The surface current densities at the frequencies 5.2, 5.9, 8.5 and $11.98 \mathrm{GHz}$ are
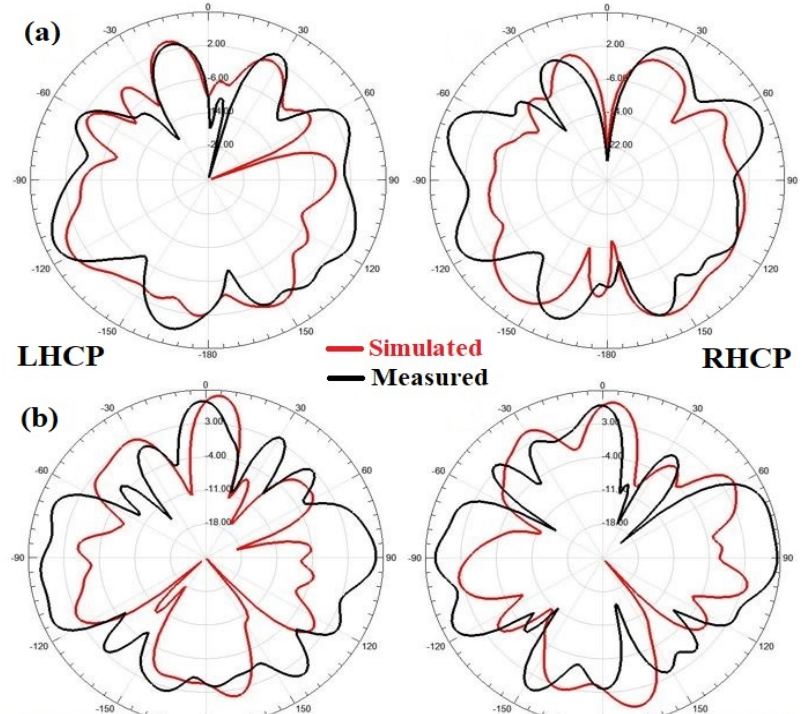

LHCP

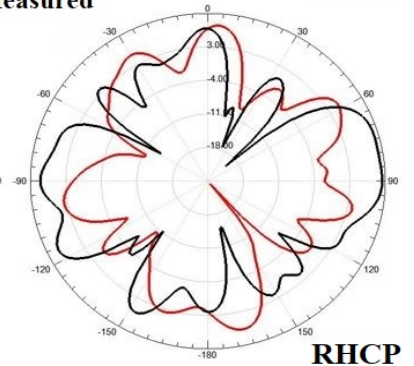

shown in Figure 8. The current intensities are concentrated along the axis of the feed line at 5.2 and $5.9 \mathrm{GHz}$, whereas at 8.5 and $11.98 \mathrm{GHz}$, the current intensities are focused at the edges of the feed line and the radiating element.

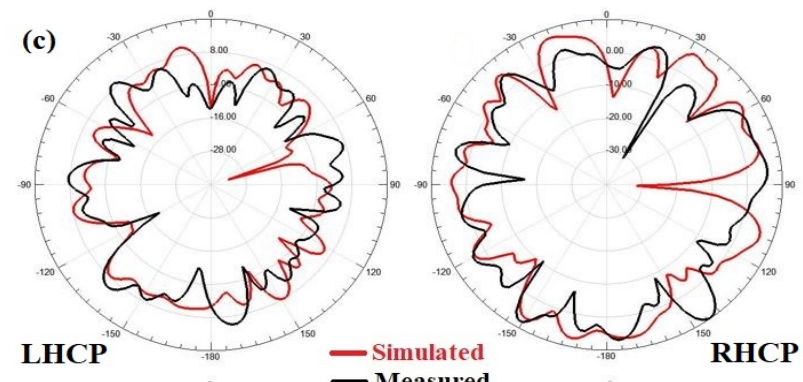

(d)
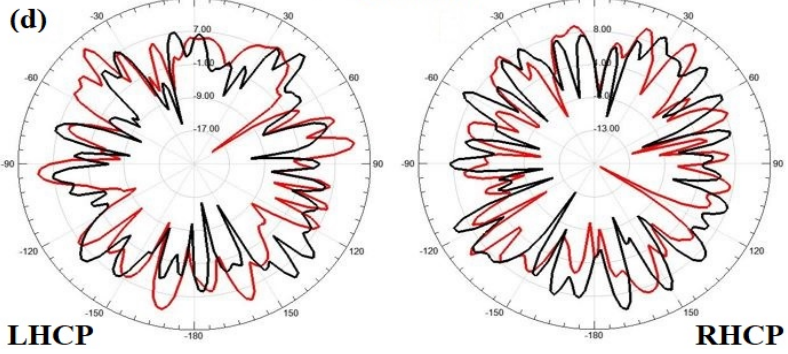

Fig. 5. Simulated and measured results of circularly polarized radiation patterns (LHCP \& RHCP respectively) at (a) $5.2 \mathrm{GHz}$, (b) $5.9 \mathrm{GHz}$, (c) 8.5 GHz and (d) $11.98 \mathrm{GHz}$.

The proposed antenna model has been fabricated and tested for compatibility with the simulation results by using a combinational analyser and anechoic chamber, where the measured Radiation Patterns and Return loss characteristics are obtained respectively. The measured results are in close concurrence with the simulated results, where the measured peak gains are recorded as $10.342,11.994,12.172 \& 14.076$ $\mathrm{dBs}$ at 5.2, 5.9, $8.5 \& 11.98 \mathrm{GHz}$ respectively as shown in the Figure $5(\mathrm{a}-\mathrm{d})$. The fabricated antenna model and the corresponding measured $\mathrm{S} 11(\mathrm{~dB})$ plot are presented in Figure 9(a) and 9(b) respectively.
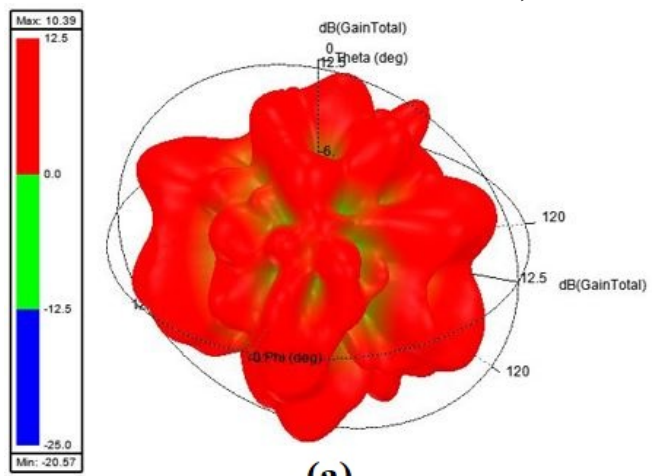

(a)
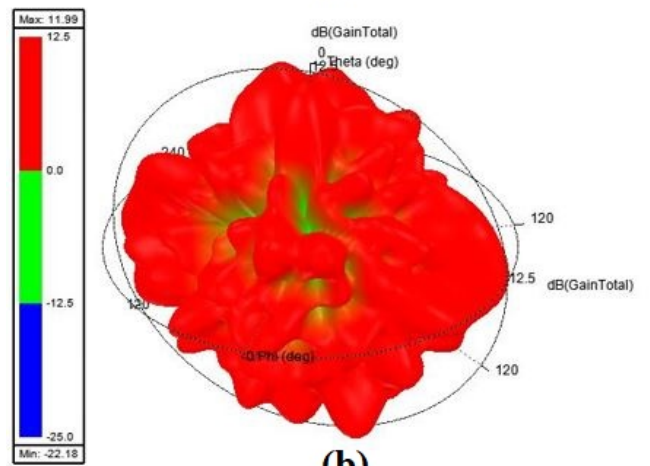

(b)

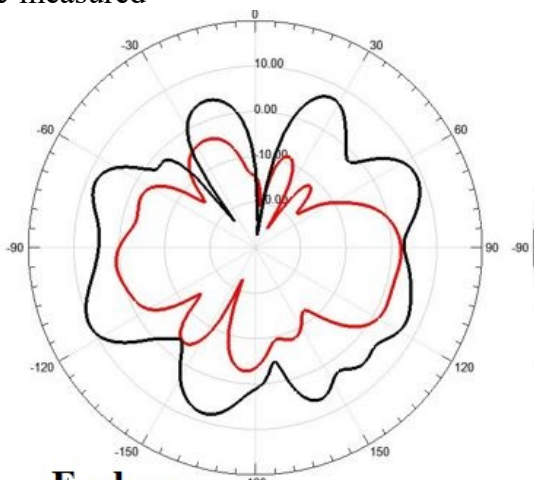

E-plane

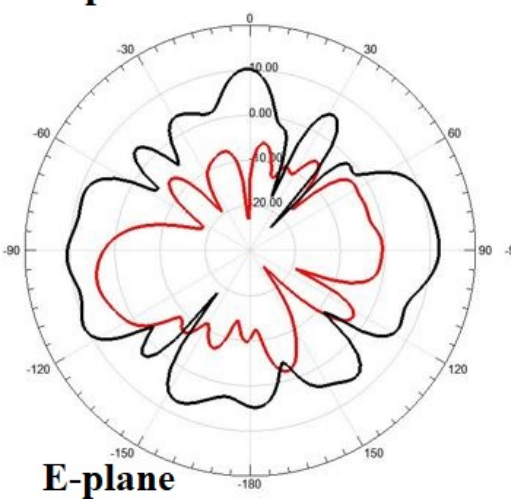

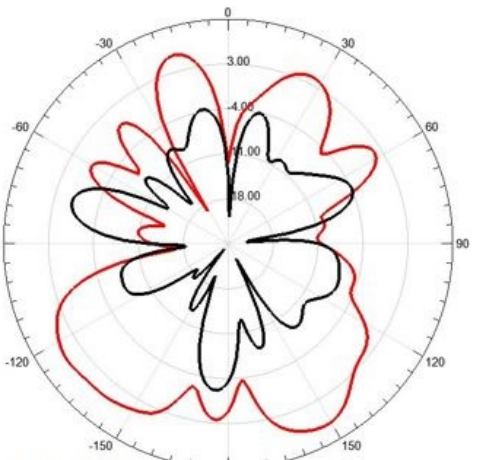

H-plane

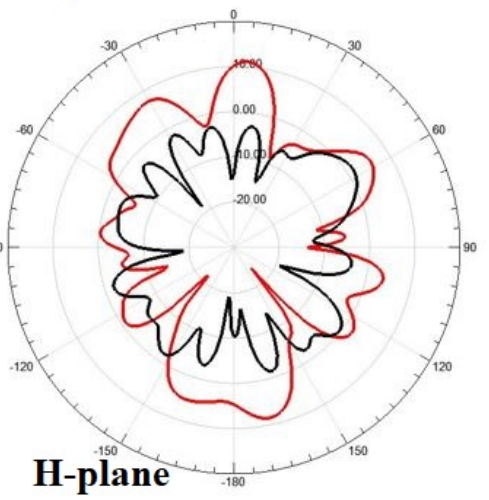


Bandhakavi. S. Deepak, Boddapati. T. P. Madhav, Badisa Anil Babu and Kosuru Sri Rama Murthy/ Journal of Engineering Science and Technology Review 14 (3) (2021) 116 - 123
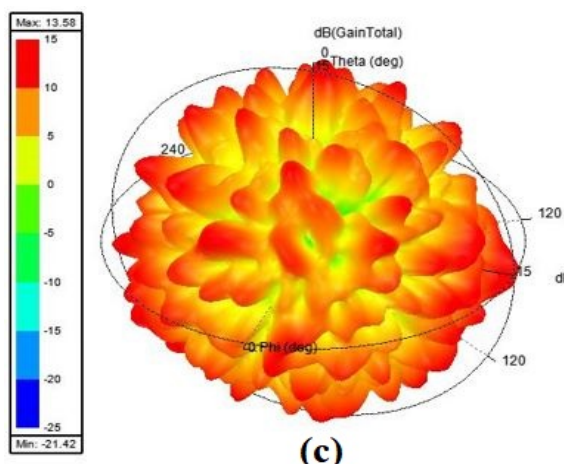

(c)
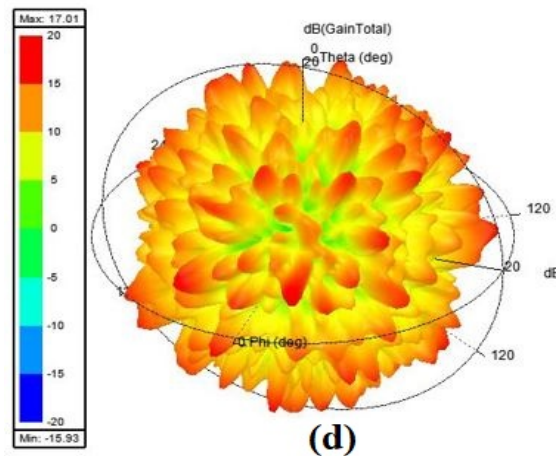

(d)

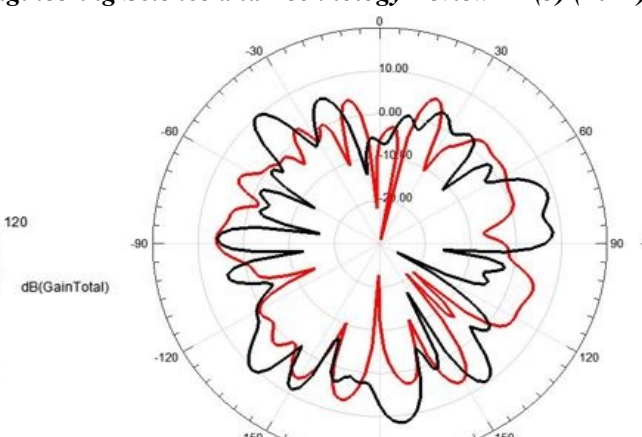

E-plane

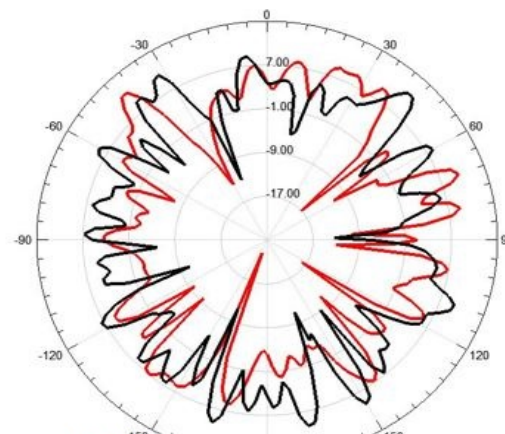

E-plane

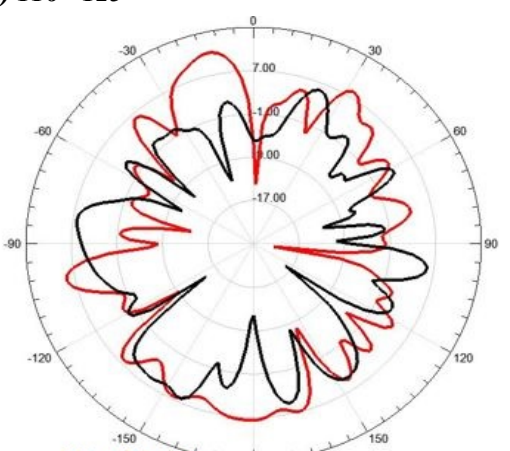

H-plane

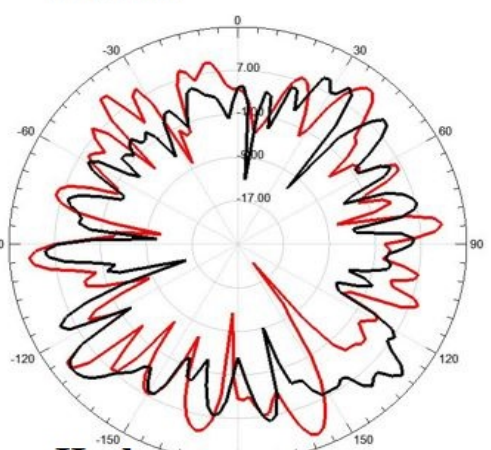

H-plane

Fig. 6. Simulated Radiation Patterns, E-plane and H-plane Patterns (with Co \& Cross Polarizations) at (a) $5.2 \mathrm{GHz}$, (b) $5.9 \mathrm{GHz}$, (c) $8.5 \mathrm{GHz}$ and (d) $11.98 \mathrm{GHz}$.

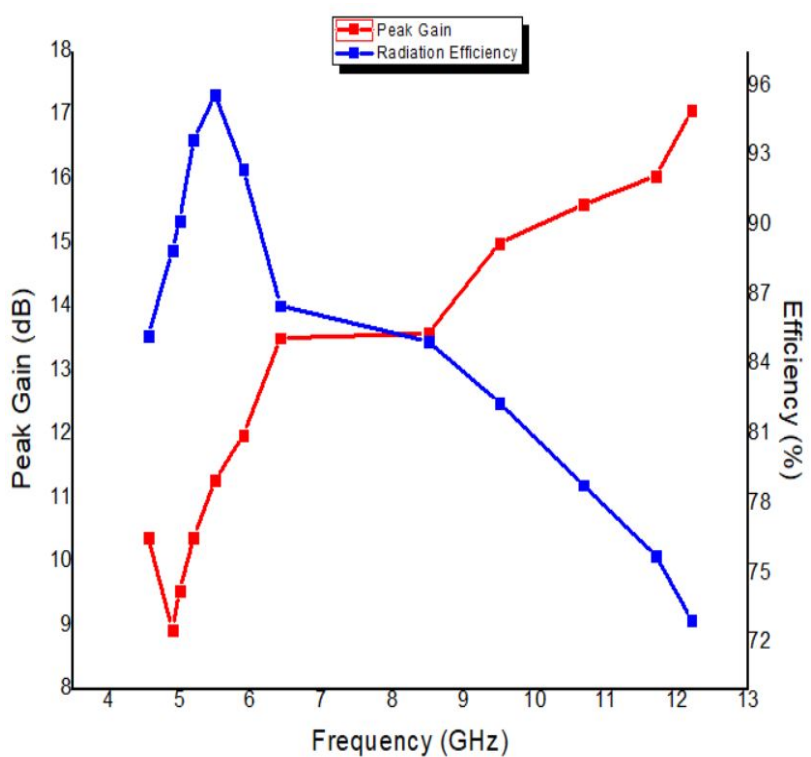

Fig. 7. Peak Gain and Radiation Efficiency Vs Frequency plot.

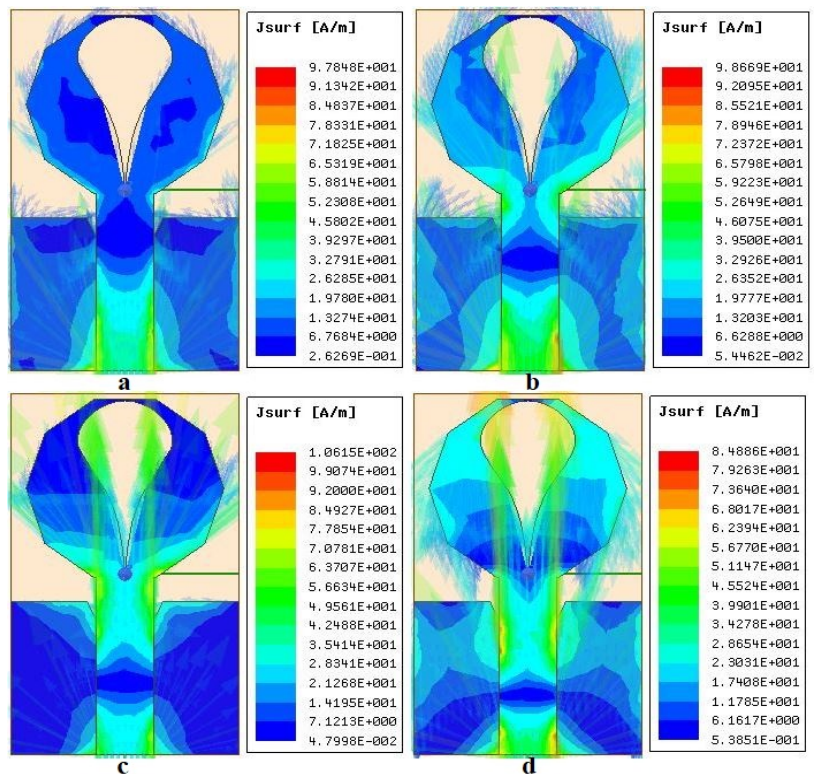

Fig. 8. Surface current densities at (a) $5.2 \mathrm{GHz}$ (b) $5.9 \mathrm{GHz}$ (c) $8.5 \mathrm{GHz}$ \& (d) $11.98 \mathrm{GHz}$.
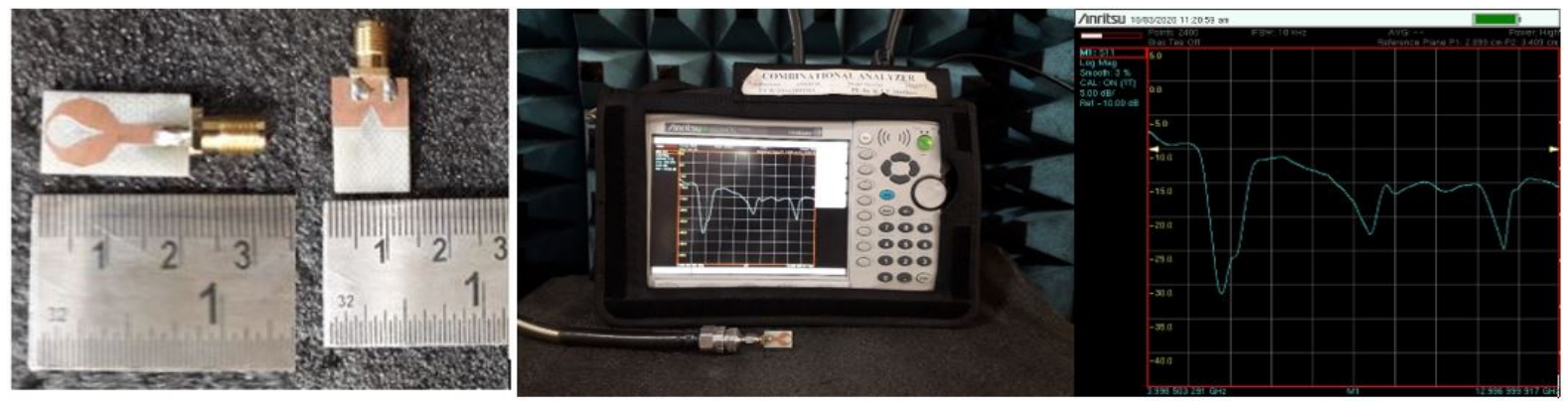

Fig. 9. (a) Fabricated Antenna Model \& (b) Measured Return loss characteristics of the proposed antenna model 
Table 4. Comparison of proposed model with other antenna designs

\begin{tabular}{c|c|c|c|c}
\hline S.No & Reference & Size $\left(\boldsymbol{l} \times \mathbf{w} \mathbf{m m}^{2}\right)$ & Peak Gain (dB) & Operating Band/s (GHz) \\
\hline 1 & {$[1]$} & $37 \times 56$ & 4.8 & $2.24-2.50,3.60-3.99,4.40-4.60 \& 5.71-$ \\
2 & {$[2]$} & $36 \times 24$ & 6.13 & $3-8.5 \& 10-12$ \\
3 & {$[3]$} & $60 \times 50$ & Not Mentioned & $5.699,10.108,11.100,15.812 \& 17.621$ \\
4 & {$[4]$} & $41.5 \times 37$ & 20.1 & $1.67,2.42,3.58,4.55,7.34,8.05 \& 9.52$ \\
5 & {$[5]$} & $100 \times 100$ & 1 & $3.0-14.1$ \\
6 & {$[6]$} & $150 \times 150$ & 9.75 & $0.824-0.960 \& 1.710-2.165$ \\
7 & {$[7]$} & $38 \times 36$ & 5 & $3-21.5$ \\
9 & Proposed & $20 \times 12$ & 3.11 & $3.74-13.85$ \\
\hline
\end{tabular}

\section{Conclusion}

A novel curvature slot impregnated decagonal microstrip patch antenna with defected ground structure with miniaturized dimensions $(20 \times 12 \mathrm{~mm})$ has been designed and analysed for its performance w.r.t operating bandwidth, gain and polarization. In the process of analysis, it is observed that the proposed antenna with optimized semisymmetric curvature slot on the patch along with the Vgroove in the ground plane have contributed quite significantly in achieving wide operating Bandwidth of 7.86 $\mathrm{GHz}$ (from 4.56 to $12.42 \mathrm{GHz}$ ), extremely impressive Peak $(17 \mathrm{~dB})$ and Average Gains $(12.96 \mathrm{~dB})$, as well as, Circular Polarization for the frequencies as mentioned in Table 2. The measured results of the fabricated antenna have shown good agreement with the simulated results and found many applications like ISM, WLAN, Wi-Fi, WiMAX, ITU Radar and Satellite bands. A quick comparison of proposed antenna model with other antenna designs has been displayed in Table 4, which clearly depicts that the proposed antenna model has been the best in terms of size, as well as the gains achieved over wide bandwidth.

\section{Acknowledgements \\ SR/FST/ET-II/2019/450}

This is an Open Access article distributed under the terms of the Creative Commons Attribution License.

\section{References}

1. Sanjay Chouhan, Debendra Kumar Panda, Vivek Singh Kushwah \& Sarthak Singhal, "Spider shaped fractal MIMO antenna for WLAN/WiMAX/Wi-Fi/ Bluetooth/C-band applications", International Journal of Electronics and Communications (AEÜ), $152871,2019$.

2. Majed O. Dwairi, Mohamed S. Soliman, Ahmad A. Alahmadi, Sami H. A. Almalki \& Iman I. M. Abu Sulayman, "Design and Performance Analysis of Fractal Regular Slotted-Patch Antennas for Ultra-Wideband Communication Systems", Wireless Personal Communications, 2019.

3. Mohd Gulman Siddiqui, Abhishek Kumar Saroj, Devesh Tiwari \& Saiyed Salim Sayeed, "Koch-Sierpinski Fractal Microstrip antenna for C/X/Ku-band applications", Australian Journal of Electrical and Electronics Engineering, DOI: 10.1080/1448837X.2019.1677121, 2019.

4. Inkwinder Singh Bangi \& Jagtar Singh Sivia, "Moore, Minkowski and Koch Curves Based Hybrid Fractal Antenna for Multiband Applications", Wireless Personal Communications, 2019.

5. J. A. Tirado-Mendez, D. Martinez-Lara, H. Jardon-Aguilar, R. Flores-Leal, and E. A. Andrade-Gonzalez, "Inscribed Fibonacci Circle Fractal in a Circular Radiator for Ultra-Wideband Antenna Operation and Size Reduction", International Journal of Antennas and Propagation, Article ID 6393401, 2019.

6. R. L. Farias, D. L. Lemes, J. M. Vieira, M. V. T. Heckler \& A. F. T. Salazar, "Dual-Port Dual-Wideband Annular Slot Antenna with Stable Unidirectional Pattern", Journal of Microwaves, Optoelectronics and Electromagnetic Applications, Vol. 17 No. 1, March 2018.

7. Aliakbar Dastranj, Fatemeh Ranjbar, \& Mosayeb Bornapour, "A New Compact Circular Shape Fractal Antenna for Broadband Wireless Communication Applications", Progress In Electromagnetics Research C, Vol. 93, 19-28, 2019.

8. Ushaben Keshwala, Sanyog Rawat, Kanad Ray, "Honeycomb shaped Fractal Antenna with Defected Ground Structure for UWB applications", 6th International Conference on Signal Processing and Integrated Networks (SPIN), 2019.

9. Anilkumar T., Kotamraju S.K, "Transparent and conformal wheelshaped fractal antenna for vehicular communication applications," AEU - International Journal of Electronics and Communications, 91 (), PP. 1- 10, 2018.

10. Nadh B.P., Kumar M.S., Rao M.V., Anilkumar T. (2018), 'Asymmetric ground structured circularly polarized antenna for ISM and WLAN band applications', Progress In Electromagnetics Research M, 76 (), PP. 167- 175.

11. Priya P.P., Khan H., (2017), "Defected ground structure circularly polarized wideband antennas for wireless communication applications", Journal of Advanced Research in Dynamical and Control Systems, 9 (SpeccialIssue18), PP.122-130.

12. Ramkiran D.S., Anusha B.L., Bhargavi T.L., Reddy L.V., Yashwanth P., Anilkumar T. (2017), "Pentagonal shaped koch fractal monopole slot antenna for multiband applications", ARPN Journal of Engineering and Applied Sciences,12(15), PP.43904396.

13. Sowjanya B., Govardhani I., Saikiran V., Triveni Y.L., Sushma N., Rehana S. (2017), "Analysis of inverted suspended circular patch antenna loaded with a square patch for LTE radar applications", Journal of Advanced Research in Dynamical and Control Systems, 9(), PP.2212-2218.

14. Anilkumar T. (2018), 'Design and study of multiband planar wheel-like fractal antenna for vehicular communication applications', Microwave and Optical Technology Letters, 60 (8), PP. 1985- 1993.

15. Sheik A.R., Krishna K.S.R., (2018), "Circularly polarized defected ground broadband antennas for wireless communication applications", Lecture Notes in Electrical Engineering, 434 (), PP. 419- 427.

16. Reddy T.S., Singh S., Rao P.K., Saheb S.N., Alli A.K.B., Venkateswarlu M. (2018), "A Star Polygon with Concentric 
Bandhakavi. S. Deepak, Boddapati. T. P. Madhav, Badisa Anil Babu and Kosuru Sri Rama Murthy/

Journal of Engineering Science and Technology Review 14 (3) (2021) 116 - 123

Circular slot DGS for Wlanlwimax Applications", Proceedings of the 2nd International Conference on Electronics, Communication and Aerospace Technology, ICECA 2018, (),PP. 1548- 1551.

17. Venu Madhav P., Siva Ganga Prasad M. (2019), "Fabrication of hybrid fractal microstrip antenna for mobile and wi-max applications", International Journal of Innovative Technology and Exploring Engineering, 8(11), PP.3373-3377.
18. Kumar S., Manikanta, Sekhar S., Sankar P., Risheek R. (2019), "Design of circular patch antenna for enhancing field strength", Journal of Advanced Research in Dynamical and Control Systems, 11(1), PP.492-496. 